\title{
Improvement of acidification on dewaterability of oily sludge from flotation
}

\author{
Shuhai Guo ${ }^{\mathrm{a}, *}$, Gang $\mathrm{Li}^{\mathrm{a}}$, Jiuhui Qu ${ }^{\mathrm{b}}$, Xilin $\mathrm{Liu}^{\mathrm{c}}$ \\ a Institute of Applied Ecology, Chinese Academy of Sciences, Shenyang 110016, PR China \\ ${ }^{\mathrm{b}}$ Research Center for Eco-environmental Science, Chinese Academy of Sciences, Beijing 100085, PR China \\ ' Liaohe Company Oilfield, CNPC, Panjin 124010, PR China
}

\section{A R T I C L E I N F O}

\section{Article history:}

Received 28 October 2010

Received in revised form 18 January 2011

Accepted 20 January 2011

\section{Keywords:}

Oily sludge

Acidification

Floc breakage

Dewaterability

\begin{abstract}
A B S T R A C T
This paper presents the improvement of acidification on the dewaterability of oily sludge from a flotation process. Various parameters, including the volume of supernatant water, capillary suction time (CST), and specific resistance to filtration (SRF) were used to evaluate the dewaterability of oily sludge. In addition, floc size distribution and release rates of $\mathrm{Al}(\mathrm{III})$ were used to explain skeleton breakage as a result of the acidification treatment. Results show that dewaterability increased obviously as the sludge $\mathrm{pH}$ decreased. After $120 \mathrm{~min}$ of settling, the volume of supernatant water reached $77 \%$ at $\mathrm{pH} 4.0$. Maximum reductions in CST and SRF were 93.1\% and 89.2\%, respectively. Following acidification, the flocs in the oily sludge achieved a broader particle size distribution and a smaller median diameter [d (0.5)] of $36.0 \mu \mathrm{m}$ (cf. $74.4 \mu \mathrm{m}$ for the raw sample). In addition, lower $\mathrm{pH}$ led to a greater rate of release of $\mathrm{Al}(\mathrm{III})$. This study verifies that the floc skeleton of oily sludge can be broken through the dissolution of aluminum hydroxide; i.e., acidification enhances the dewaterability of oily sludge by changing the floc structure. All results indicate that acidification is advisable as a pretreatment of oily sludge.
\end{abstract}

(c) 2011 Elsevier B.V. All rights reserved.

\section{Introduction}

Chemical coagulation and flocculation have been widely employed for several decades to remove suspended solids and oil from oil produced water in an oilfield [1,2]. In the flotation process, granular and amorphous flocs are generated as a result of solid particles and oil agglomerating with alum coagulants. These flocs become a semi-solid oily sludge upon flocculation with organic polymers, amounting to $0.01 \mathrm{t} / \mathrm{m}^{3}$ of crude oil produced in the oilfield. The oily sludge from flotation is a special kind of hazardous waste, generally containing different concentrations of water (90-99 wt\%), waste oil (0.5-3 wt\%), and mineral particles $(0.2-2 \mathrm{wt} \%)$. After dewatering, the sludge is usually disposed by incineration or remediation $[3,4]$. However, it is widely known that dewaterability of oily sludge is poor. Volume reduction of excessive oily sludge is becoming a major industrial problem that must be dealt with appropriately.

Dewatering of oily sludge usually involves the use of mechanical force. Generally, pressure filtration is one means of condensing the sludge to separate water from the oily sludge $[5,6]$. This mechanical dewatering method does not, however, achieve the desired effect without some form of pretreatment, primarily because it is dif-

\footnotetext{
* Corresponding author.

E-mail addresses: shuhaiguo@iae.ac.cn (S. Guo), ligang@iae.ac.cn, lg2957@yahoo.cn (G. Li).
}

ficult to expel the water located within the skeleton of the oily sludge when $\mathrm{Al}(\mathrm{OH})_{3}$ precipitates are the dominant species in the floc formation. During the flotation process, water is trapped within crevices of the floc matrix formed by solid particles, oil and $\mathrm{Al}(\mathrm{OH})_{3}$. Therefore, it is necessary to release water within the oily sludge prior to its separation by mechanical force.

Although the release of water by breaking the floc structure has been proposed [7], some findings suggest that exited methods of breaking skeleton may not be suitable for oily sludge, especially heavy oily sludge. Previous studies have reported that freeze/thaw processing can significantly improve certain sludge dewatering characteristics [8-10]. This physical approach can irreversibly change the floc's structure into a more compact form, thereby reducing the interstitial water content of sludge. However, the use of this method has only been reported for separating "oil" phase of sludge, in which the weight fraction of oil is 22.9 (wt\%), and is not suitable for the release of water in oily sludge produced from flotation. Most other dewatering approaches for treating sludge have poor applicability and effectiveness; for example ultrasonication [11] is very difficult to perform and electro-kinetic treatment $[12,13]$ consumes relatively high amounts of energy. It can be seen, therefore, that existing methods for the release of water are currently quite inefficient with regard to their application in oilfields at the industrial scale. Moreover, the mechanisms of water release in oily sludge produced from flotation should be discussed.

As the end product of dissolved air flotation, oily sludge possesses many characteristics that are similar to alum sludge. 


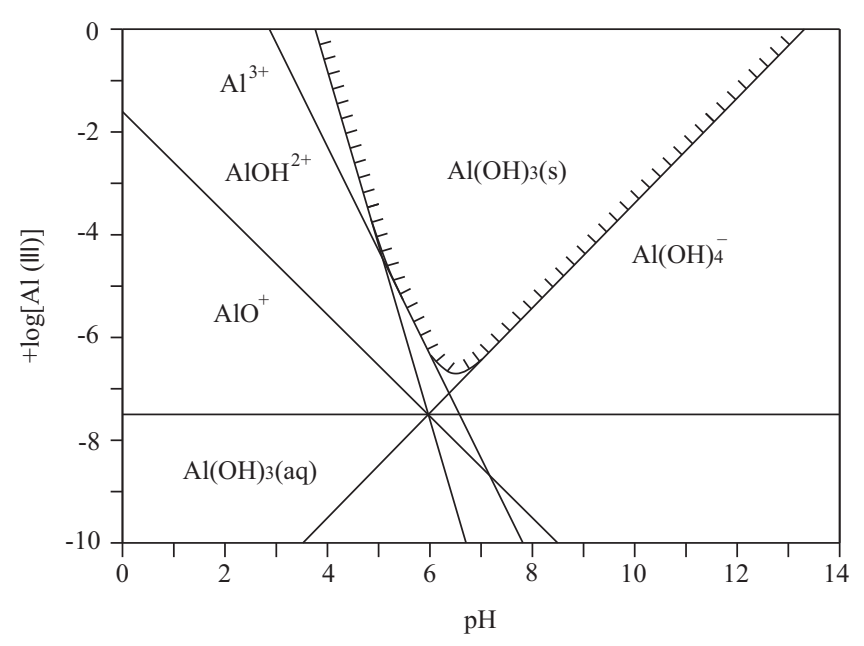

Fig. 1. $\mathrm{PH}$ value dependence of $\mathrm{Al}(\mathrm{III})$ in equilibrium with amorphous $\mathrm{Al}(\mathrm{OH})_{3}$.

Therefore, it is appropriate to consider tackling the problem according to the principle of coagulation/flocculation. Most researches on coagulation refer to the effect of $\mathrm{pH}$ on pollutant removal and sludge characteristics [14-17], and so in this context oily sludge can be considered quite similar as it too is affected by $\mathrm{pH}$ adjustment. Fig. 1 is a typical simplified solubility diagram for aluminum hydroxide [18]. At the correct $\mathrm{pH}$, the addition of coagulant forms aluminum hydroxide, and the destabilized colloids in oil wastewater become enmeshed within the flocs of the hydroxide. The skeleton of the flocs makes it difficult to pack the sludge aggregates, resulting in more interstitial bound water being contained in the oily sludge, leading to poor settleability. Existing dewatering techniques are inefficient at breaking the coagulant chemical bonds. Therefore, improving the dewatering efficiency-in particular, allowing more interstitial water to leave the oily sludge surface-requires the breaking of flocs in the oily sludge.

Acidification of sludge for volume reduction and coagulant recovery $[19,20]$ enhances the dewatering efficiency and settling apeed of sludge, breaking the skeleton of the flocs to release aluminum back into solution. There is, however, very little published research on the dewatering characteristics and floc properties of oily sludge following acidification, especially with regard to variations in particle size during the floc skeleton breakage process. Even in existing examples of dewatering in other sludge types, only the dewaterability and recycling of alum have been described widely $[21,22]$.

The aim of this paper is to investigate the improvement of acidification on dewaterability of oily sludge obtained from flotation. An attempt is also made to have an insight into the variation of floc microstructure and particles size distribution. Besides, the degree of volume reduction and the release of $\mathrm{Al}(\mathrm{III})$ are also studied to illustrate the effect of acidification.

\section{Materials and methods}

\subsection{Materials}

Several batches of oily sludge, generated from alum coagulation and dissolved air flotation (DAF), were obtained from a heavy oil produced water plant located in the Liaohe Oilfield, Liaoning Province, northeastern China. Analysis revealed that the experimental sludge had the following characteristics: $\mathrm{pH}: 7.3 \pm 0.3$; water content: $98.2 \pm 0.7 \%(\mathrm{w} / \mathrm{w})$; total solid content: $1.1 \pm 0.4 \%$ $(\mathrm{w} / \mathrm{w})$; oil content: $0.7 \pm 0.3 \%(\mathrm{w} / \mathrm{w})$; capillary suction time (CST):
$1720 \mathrm{~s}$; and specific resistance to filtration (SRF): $3.7 \times 10^{16} \mathrm{~m} \mathrm{~kg}^{-1}$. The aluminum content of the wet sludge was $3400 \mathrm{mg} \mathrm{kg}^{-1}$.

\subsection{Experimental procedure}

After determining the sludge characteristics for each $\mathrm{pH}$ level, heterogeneous oily sludge samples (ca. $200 \mathrm{~mL}$ ) were stirred for $5 \mathrm{~min}$ at $60 \mathrm{rpm}$ in a beaker at a fixed $\mathrm{pH}$, controlled by adding $1 \mathrm{M}$ sulfuric acid, at room temperature $\left(23 \pm 1^{\circ} \mathrm{C}\right)$. The acidified sludge was poured into a $100-\mathrm{mL}$ measuring cylinder and left to settle quiescently, with the volume of supernatant water recorded every $10 \mathrm{~min}$. After $120 \mathrm{~min}$, the supernatant water was siphoned off and then analyzed to determine the release rates of $\mathrm{Al}(\mathrm{III})$. The dewatering behavior of the sludge was evaluated by analyzing the CST and SRF of the acidified settled sludge.

Another portion of the heterogeneous sample $(100 \mathrm{~mL})$ at $\mathrm{pH}$ 5.0 was subjected to a jar test to measure the characteristic variation between the raw and acidified sludge. The desired raw sludge was transferred into the experimental apparatus and the morphology and particles size distribution of the flocs were measured (see Section 2.3).

\subsection{Analysis}

The composition, microstructure, and particle size distribution of the oily sludge were determined, with the oil and moisture content measured according to existing procedures [23]. The morphology of the flocs was examined using an environment scanning electron microscope (ESEM) (XL-30ESEM, The Netherlands). The oily sludge was first diluted with an appropriate dosage of distilled water and then the particle size distribution in the mixture was analyzed using a Malvern Mastersizer 2000 analyzer (Malvern, UK). This also provided the data for the following parameters: volume-average diameter, specific surface area, trail distance, and consistency. The adjusted $\mathrm{pH}$ of the sludge was monitored using a $\mathrm{pH}$ meter (PHS-3B, China).

Samples for the $\mathrm{Al}(\mathrm{III})$ analysis were first filtered through 0.45 $\mu \mathrm{m}$ qualitative filter paper (Made in Xi'an), and the analysis itself was performed using the standard method [23]. Total Al(III) concentration in the raw sludge was obtained after digesting the sludge with acid and hydrogen dioxide at $95 \pm 5^{\circ} \mathrm{C}$, following the method as prescribed by the US Environmental Protection Agency (USEPA) [22].

Both CST and SRF were analyzed to assess the dewaterability and filterability of the sludge. CST was analyzed at a constant temperature of $25^{\circ} \mathrm{C}$ using standard CST apparatus (Type $304 \mathrm{M}$, China). SRF analysis was performed using a Büchner funnel and Whatman No. 42 filter paper at $44 \mathrm{kPa}$ under vacuum conditions. Three batches of each sample were used to obtain an average value.

\section{Results and discussion}

\subsection{Effect of acidification on the dewatering characteristics of oily sludge}

\subsubsection{Settleability}

The settleability of the oily sludge after acidification was monitored for $120 \mathrm{~min}$. Fig. 2 displays the variation in the volume of the supernatant water during this settling period for both the raw oily sludge and the acidified sludge samples. It is clear from the results that there was a dramatic difference between them. The settling performance of the raw oily sludge ( $\mathrm{pH} 7.3$ ) was extremely poor; it was difficult to even observe the settling process, or indeed a clear interface between the liquid and solid phases. In contrast, the settling interface in the acidified samples ( $\mathrm{pH} 6.0,5.0,4.0)$ was 


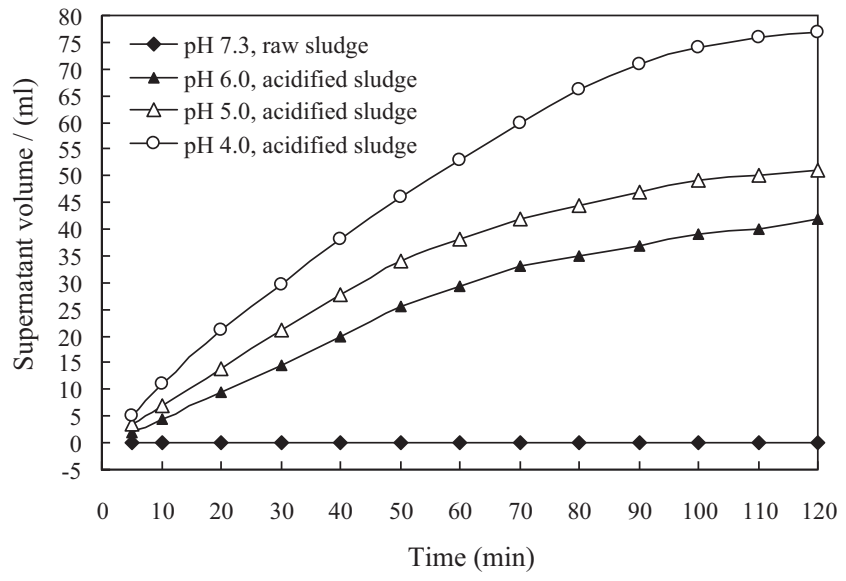

Fig. 2. Settling curve of oily sludge after treatment by acidification.

more pronounced. The acidified sludge transformed into a clear supernatant fluid with an underlying dark sediment. There was a dramatic rise in the volume of supernatant water when the $\mathrm{pH}$ was less than 6.0; the volume at $\mathrm{pH} 4.0$ was much greater than at $\mathrm{pH} 6.0$ or $\mathrm{pH}$ 5.0. After $60 \mathrm{~min}$ of settling at $\mathrm{pH} 6.0,5.0$, and 4.0, the volumes of supernatant water were $29.0,38.0$, and $53.0 \mathrm{~mL}$, respectively; after $120 \mathrm{~min}$, values reached $42.0,51.0$, and $77.0 \mathrm{~mL}$, respectively. Thus, approximately $77 \%$ of the water volume in the oily sludge could be separated after acidification at $\mathrm{pH}$ 4.0. Furthermore, the dewatering efficiency of the oily sludge at all the tested $\mathrm{pH}$ levels improved as the treatment time increased, albeit relatively slowly after $100 \mathrm{~min}$. Lower-pH treatment was more effective at improving the settling speed of the sludge. It appears that good settleability in oily sludge always corresponds to good dewaterability [24].

The results and observations described above reveal that, in the present set of experiments, the settleability of sludge was highly influenced by acidification pretreatment. As the settling time progressed, the water and compression zones gradually increased, while the uniform zone gradually decreased and the transition zone remained almost unchanged. However, after the uniform zone had diminished, then the transition zone also began to reduce. The compression zone was then packed until reaching its maximum solid density. After the settling process was complete, the supernatant water in the acidic samples was separated and neutralized by the application of alkali. The effluent could then be treated further using existed methods [25].

\subsubsection{CST and SRF}

Both CST and SRF are used widely to evaluate sludge dewatering behavior [26-29]. Fig. 3 reveals significant decreases in the values of both CST and SRF upon decreasing the $\mathrm{pH}$, with minimum values at $\mathrm{pH}$ 2.0. The CST and SRF of the raw oily sludge were approximately $1720 \mathrm{~s}$ and $3.7 \times 10^{16} \mathrm{~m} \mathrm{~kg}^{-1}$, respectively, consistent with its comparatively poor dewaterability. At $\mathrm{pH} 2.0$, the SRF reduction efficiency $\left(89.2 \%\right.$; $\left.\mathrm{SRF}_{\min }=0.4 \times 10^{16} \mathrm{~m} \mathrm{~kg}^{-1}\right)$ and the CST reduction efficiency $\left(93.1 \%\right.$; $\mathrm{CST}_{\min }=118 \mathrm{~s}$ ) were both maximized. The CST of the raw sample was approximately 14 times that of the acidified sludge, indicating that acidification was an appropriate means of treatment for the release of water. However, to adjust the $\mathrm{pH}$ to 2.0 during the course of the experiment required a large volume of acid, and such an excessive amount quickly led to corrosion of the apparatus.

The dewaterability is dependent on breakage of the flocs during acidification treatment; similar effects of acidification have been observed previously [21]. In general, acidification reduces the CST and SRF because it causes the zeta potential of the sludge particles to approach neutrality, resulting in superior sludge dewatering

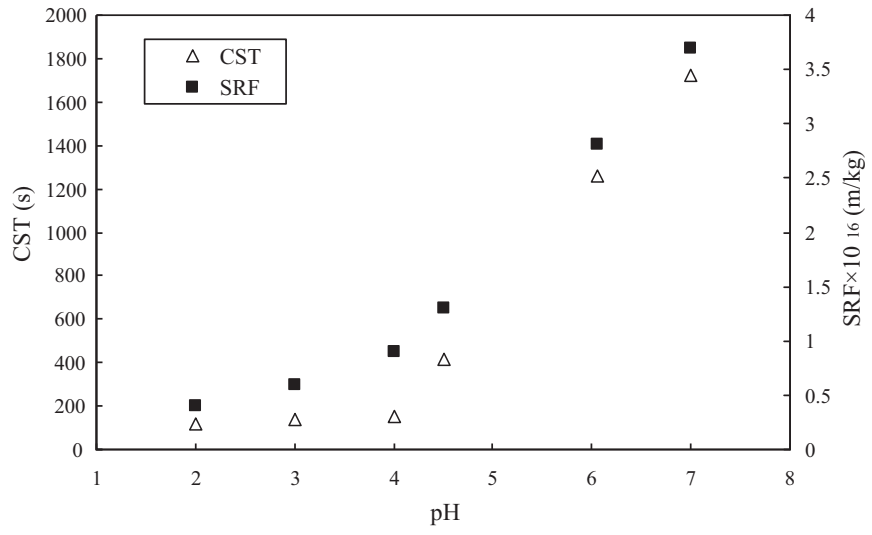

Fig. 3. Effect of acidification on the CST and SRF of treated sludge.

[30]. However, as a complex floc, oily sludge is much more stable due to its mixture of oil and clay. It is impossible to break the structure of the sludge completely by merely neutralizing surface charges. Nevertheless, we found that during the sludge acidification process, the diffuse sludge flocs were broken into smaller fragments, thereby improving the dewaterability when these particles deflocculated. The dissolution of aluminum hydroxide and the breakage of the floc skeletons have a significant impact on the performance of sludge dewatering. This behavior was confirmed by the analysis of variation in the properties of flocs, as will now be described.

\subsection{Effect of acidification on floc properties}

\subsubsection{Variation of floc microstructure}

Scanning electron microscope (SEM) micrographs have been used previously to examine the floc microstructure of sludge mixed with aluminum hydroxide [31]. In this study, however, surface morphology of the oily sludge was monitored using ESEM, which permits the observation of hydrated samples in their native states, without the need to coat the insulators with a conducting layer. In the ESEM micrographs produced, the intact floc skeleton was a suitable structure with which to observe the relationship between dewaterability and microstructure.

Fig. 4 displays ESEM micrographs of typical flocs before and after acidification treatment. The texture of the floc in the raw sludge was comparatively uniform; its appearance was rather porous and feathery. After acidification and dewatering, however, more crannies were present in the microstructure, giving an overall appearance of a network. The structure of the floc in the oily sludge was damaged greatly during the acidification process due to the dissolution of aluminum hydroxide. The bonds of the alum coagulants in the flocs were broken, causing the water trapped in the flocculated particles to be released. The whole structure subsequently remained held together by the original arms.

The traditional approach to pretreating sludge is to enhance its dewaterability through the use of 'skeleton builders'; most commonly, the addition of conditioning reagents such as lime, gypsum and fly ash $[32,33]$. Such methods can greatly reduce the compressibility and increase the porosity of the sludge cake, and work by improving floc formation and providing water-transmitting passages assembled by the skeleton builders [34]. When the conditioned sludge is dewatered by pressure filtration, these skeletons can cause cake void closure which impedes continued dewatering [35]. In contrast, our findings suggest that transforming the flocs into more compact forms and breaking the skeleton builders are more important in the release of water. In our process, following the broadening of crannies, surface tension diminished [36], and 

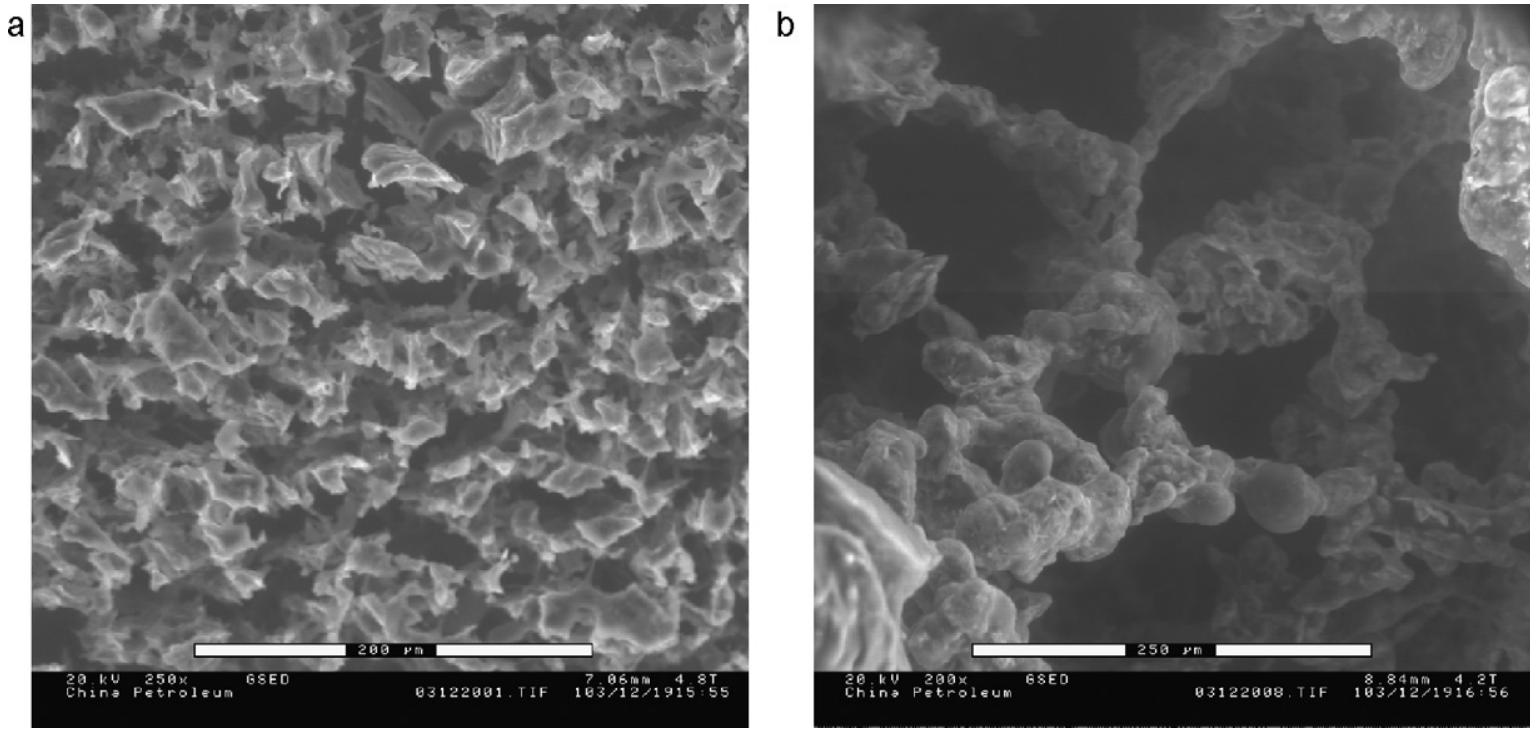

Fig. 4. ESEM micrographs of the flocs in (a) raw and (b) acidified oily sludge samples.

the release of water become easier. The process is more suitable when there is high content of moisture, but not for building the skeleton. After acidification treatment, heavy oil was still existed in the concentrated sludge, and so presumably the oil in residual solid coalesced into a single mass. The compact aggregated clay particles may well be suitable for further mechanical treatment.

\subsubsection{Particle size distribution}

Next, variation of the floc size distribution during the breakage process was measured. This variation reflects the dewatering efficiency of sludge treatment [37]. Fig. 5 presents the typical size distributions of the flocs before and after acidification. The size distribution of particles in the raw sample was unimodal, with a maximum value of $79.6 \mu \mathrm{m}$. In contrast, the curve of the acidified sample was a bimodal number-based sized distribution (peaks at 17.8 and $89.3 \mu \mathrm{m}$, respectively), with the majority of particles falling within a broader distribution range than those in the raw sample. The volume size distribution for the acidified sample
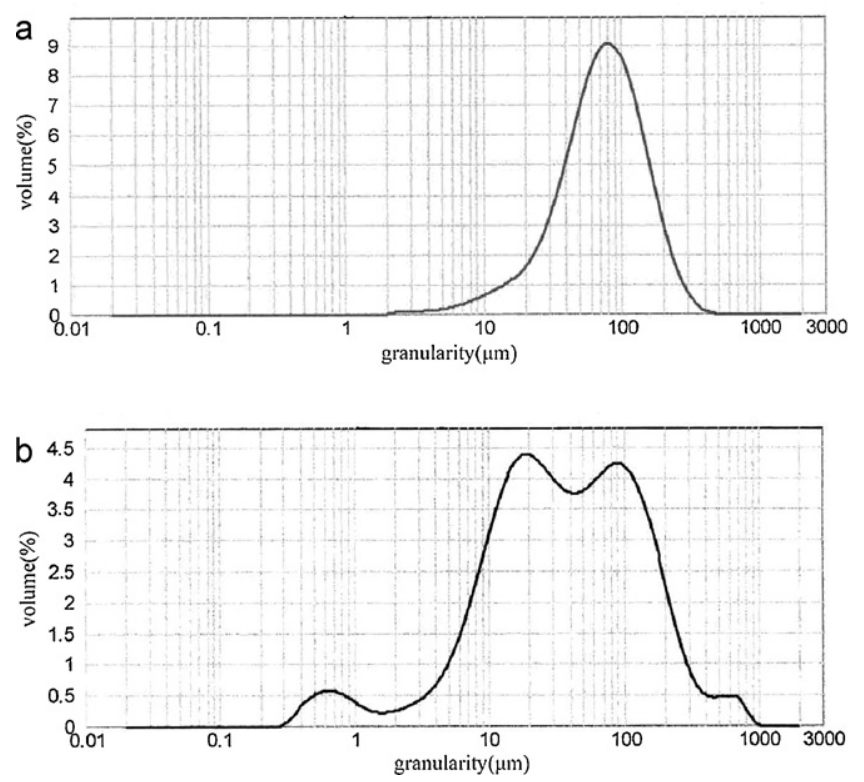

Fig. 5. Particle size distributions of (a) raw and (b) acidified sludge samples. revealed a trend toward smaller floc sizes, consistent with a distinct decrease of bonds formed through coagulation.

Table 1 summarizes the granularity parameters of the raw and acidified samples. The acidified sample had a volume-average diameter $(D[4,3])$ of $74.5 \mu \mathrm{m}$, smaller than that of the raw sample $(87.6 \mu \mathrm{m})$. The correspondingly large standard deviation (1.64) indicated a highly non-uniform distribution in the acidified sample. The median volume diameter $[d(0.5)]$ of the acidified sample was $36.0 \mu \mathrm{m}$; again, smaller than that of the raw sample $(74.4 \mu \mathrm{m})$. The specific surface area of the acidified sample, calculated from its diameter, was $0.66 \mathrm{~m}^{2} \mathrm{~g}^{-1}$ (five times that of the raw sample). The other parameters listed in Table 1 also suggest that the acidified sludge had a more compact structure than the raw sludge.

According to Fig. 5 and Table 1, we conclude that the granular distribution widened and the particle size decreased as a result of the breakage of the $\mathrm{Al}(\mathrm{OH})_{3}(\mathrm{~s})$ skeleton builders. Consequently, the structure of the floc transformed into a more compact form and the sludge-bound water was released. Nevertheless, flocs having a relatively large particle size also remained after acidification treatment. This situation is different from those in other sludge dewatering processes, such as chemical and biological sludge treatment, presumably because of polymers binding the oil and minerals.

\subsubsection{Percentage of $\mathrm{Al}(\mathrm{III})$ released after skeleton breakage}

Following acidification, the percentage of $\mathrm{Al}(\mathrm{III})$ released from the oily sludge may illustrate the extent of volume reduction achieved. This was therefore monitored at various $\mathrm{pH}$ levels for

Table 1

Granularity parameters of raw oily sludge and sludge by acidification.

\begin{tabular}{lcc}
\hline Item & Raw oily sludge & $\begin{array}{l}\text { Acidified flotation } \\
\text { oily sludge }\end{array}$ \\
\hline $\begin{array}{l}\text { Volume-average diameter } D[4,3] \\
\quad(\mu \mathrm{m})\end{array}$ & 87.6 & 74.5 \\
Specific surface area $\left(\mathrm{m}^{2} \mathrm{~g}^{-1}\right)$ & 0.13 & 0.66 \\
Trail distance & 1.88 & 4.70 \\
Consistency & 0.59 & 1.64 \\
Volume-surface area averaged & 47.4 & 9.0 \\
$\quad$ particle size $D[3,2]:(\mu \mathrm{m})$ & & \\
$d(0.1)(\mu \mathrm{m})$ & 25.9 & 6.7 \\
$d(0.5)(\mu \mathrm{m})$ & 74.4 & 36.0 \\
$d(0.9)(\mu \mathrm{m})$ & 166.1 & 176.1 \\
\hline
\end{tabular}




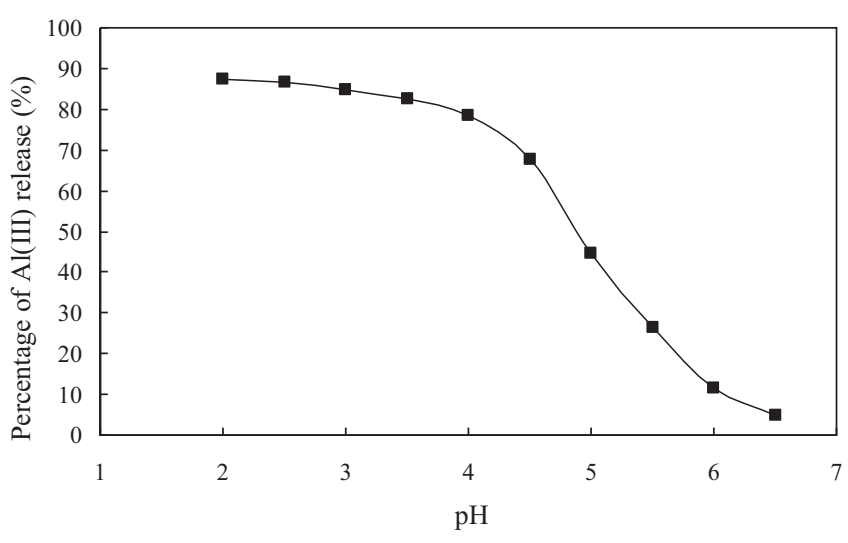

Fig. 6. Percentage of $\mathrm{Al}(\mathrm{III})$ released in oily sludge at different $\mathrm{pH}$ values.

$120 \mathrm{~min}$ after acidification to obtain the relative $\mathrm{pH}$ required to break the flocs.

The percentage of $\mathrm{Al}(\mathrm{III})$ released was calculated as follows:

$\mathrm{Al}(\mathrm{III})$ release $(\%)=\frac{C}{C_{0}} \times 100$

where $C_{0}$ is the content of $\mathrm{Al}(\mathrm{III})$ in raw sludge, and $C$ is the content of $\mathrm{Al}(\mathrm{III})$ in supernatant water after the sample has settled.

Fig. 6 reveals that a lowering of $\mathrm{pH}$ increased the percentage of $\mathrm{Al}(\mathrm{III})$ released from the sludge. At $\mathrm{pH} 4.0$, the release of $\mathrm{Al}(\mathrm{III})$ was 78.6\%; and did not increase significantly with any further reduction in $\mathrm{pH}$ (e.g., at $\mathrm{pH} 2.0$ it was only $87.4 \%$ ).

During the acidification of oily sludge, aluminum hydroxide and other substances are dissolved out; therefore, a significant reduction in the volume of sludge is expected, thereby reducing operation costs favorably. Fig. 7 reveals a linear relationship between the reduction in the amount of sludge and the release of $\mathrm{Al}(\mathrm{III})$. That is, increasing the release rate of the alum coagulant led to an increase in the reduction of sludge. According to $\mathrm{Xu}$ and Yan [21], a linear relationship exists between the reduction of sludge and the coagulant recovery. According to Fig. 7 , when the recovery rate was the same $(84.5 \%)$, the reduction of sludge was $89 \%$. Therefore, the reduction rate in oily sludge is much greater than in other wastewater sludge types (35.5\%) [21].

Above, we suggested that breakage of the skeleton is one of the most important factors influencing the dewaterability of oily sludge. During coagulation of wastewater, precipitated $\mathrm{Al}(\mathrm{OH})_{3}$ (presumed to be the dominant species inside sludge flocs) comprises the main skeleton of the flocs. In the solubility diagram for aluminum hydroxide [14] (Fig. 1), the dominant $\mathrm{Al}(\mathrm{III}$ ) species exist in the form of $\mathrm{Al}(\mathrm{OH})_{3}(\mathrm{~s})$ at $\mathrm{pH}$ 5.0-8.5. When the $\mathrm{pH}$ is outside this

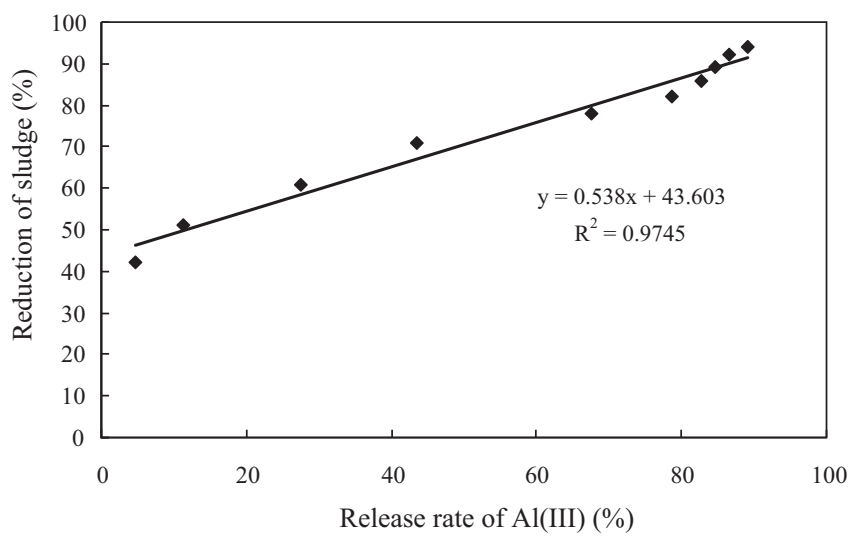

Fig. 7. Relationship between sludge reduction and the release rate of $\mathrm{Al}(\mathrm{III})$. range, $\mathrm{Al}(\mathrm{OH})_{3}(\mathrm{~s})$ transforms into soluble $\mathrm{Al}(\mathrm{III})$ species. Therefore, floc breakage is likely to be the reverse process of agglomeration, controlled through the structure of the $\mathrm{Al}(\mathrm{III})$ species. The $\mathrm{pH}$ of raw flotation oily sludge is typically 6.5-7.5. At lower $\mathrm{pH}$ values the solubility increases rapidly. Acidification could release much more water than alkalization [23].

After acidification, the settleability of the oily sludge increased and CST and SRF decreased. These results show that the dewaterability of the oily sludge was improved significantly. We can conclude, therefore, that the process of acidification helped release the water retained in flocs by breaking bonds of skeleton formed by $\mathrm{Al}(\mathrm{OH})_{3}(\mathrm{~s})$. The evidence was as follows: Firstly, as shown by the ESEM micrographs (Fig. 4), after breakage of the skeleton, surface tension diminished following the broadening of crannies, and thus the release of water became easier. Secondly, the very convincing data on the variation in the floc size distribution; not only did the floc size distribution clearly widen following acidification, but there was also a marked decrease in the median volume diameter. And finally, the percentage of $\mathrm{Al}(\mathrm{III})$ released demonstrated further the contribution of acidification to the breakage of the $\mathrm{Al}(\mathrm{OH})_{3}(\mathrm{~s})$ skeleton.

\section{Conclusions}

This study investigated the use of acidification in the reduction of oily sludge produced from flotation. Specifically, the dewaterability of the sludge and properties of the floc have been examined. From the results, the following main conclusions can be drawn:

(1) The dewaterability of the oily sludge improved significantly as a result of acidification. After $120 \mathrm{~min}$ of quiescent settlement, the oily sludge released more water at lower $\mathrm{pH}$ levels. At $\mathrm{pH} 4.0$, approximately $77 \%$ of the volume of water in the oily sludge could be separated after acidification. The reduction efficiency of CST and SRF were $93.1 \%$ and $89.2 \%$ separately at $\mathrm{pH}$ 2.0 , respectively.

(2) The release of water depended upon the breakage of the floc skeleton. After acidification, the integrity of the floc microstructure was almost completely compromised, causing the release of interstitially bound water. The size distribution of particles was therefore wider in the acidified samples, and the median volume diameter $[d(0.5)]$ was much smaller $(36.0 \mu \mathrm{m}$ and $74.4 \mu \mathrm{m}$ in the acidified and raw samples, respectively). The percentage of $\mathrm{Al}(\mathrm{III})$ released in the supernatant water showed a linear relationship with the reduction of sludge.

(3) Acidification is an efficient and cost-effective method for improving the dewaterability of oily sludge produced from flotation. It could also be used to dewater other sludge types produced from coagulation processes.

\section{Acknowledgments}

This study was supported by the Water Pollution Control and Management Project (grant no. 2009ZX07208). The authors thank the Ministry of Science and Technology, China, for partially funding this study. We also thank the Ministry of Environmental Protection, China and Key Laboratory of Pollution Ecology and Environmental Engineering, Institute of Applied Ecology, Chinese Academy of Sciences.

\section{References}

[1] A.A. Al-Shamrani, A. James, H. Xiao, Destabilization of oil water emulsions and separation by dissolved air flotation, Water Res. 36 (2002) 1503-1512.

[2] A. Fakhru'l-Razi, A. Pendashteh, L.C. Abdullah, D.R.A. Biak, S.S. Madaeni, Z.Z. Abidin, Review of technologies for oil and gas produced water treatment, J. Hazard. Mater. 170 (2009) 530-551. 
[3] J.G. Liu, X.M. Jiang, L.S. Zhou, H. Wang, X.X. Han, Co-firing of oil sludge with coal-water slurry in an industrial internal circulating fluidized bed boiler, J. Hazard. Mater. 167 (2009) 817-823.

[4] T.T. Li, S.H. Guo, B. Wu, F.M. Li, Z.X. Niu, Effect of electric intensity on the petroleum pollutants microbial degradation in Soil, J. Environ. Sci. 22 (2010) 1381-1386.

[5] J.Zall, N. Galil, M. Rehbun, Skeleton builders for conditioning oily sludge, JWPCF 59 (1987) 699-706.

[6] D.S. Jean, D.J. Lee, Expression deliquoring of oily sludge from a petroleum refinery plant, Waste Manage. 19 (1999) 349-354.

[7] R.C. Sonntag, W.B. Russel, Structure and breakup of flocs subjected to fluid stresses: I. Shear experiments, J. Colloid Interface Sci. 113 (1986) 399-413.

[8] D.S.Jean, C.P.Chu, D.J. Lee, Freeze/thaw treatment of oily sludge from petroleum refinery plant, Sep. Sci. Technol. 36 (2001) 2733-2746.

[9] D.S. Jean, D.J. Lee, J.C.S. Wu, Separation of oil from oily sludge by freezing and thawing, Water Res. 33 (1999) 1756-1759.

[10] C.K. Lai, G.H. Chen, M.C. Lo, Salinity effect on freeze/thaw conditioning of activated sludge with and without chemical addition, Sep. Purif. Technol. 34 (2004) $155-164$.

[11] X. Yin, X.P. Lu, P.F. Han, Y.R. Wang, Ultrasonic treatment on activated sewage sludge from petro-plant for reduction, Ultrasonics 44 (2006) 397-399.

[12] L. Yang, G. Nakhla, A. Bassi, Electro-kinetic dewatering of oily sludges, J. Hazard. Mater. 125 (2005) 130-140.

[13] S. Habibi, A New Electrokinetic Technology for Revitalization of Oily Sludge, Ph.D. Thesis, Department of Building, Civil, and Environmental Engineering, Concordia University, Quebec, Canada, 2004.

[14] A. Garg, I.M. Mishra, S. Chand, Thermo-chemical precipitation as a pretreatment step for the COD and colour removal from pulp and paper mill effluent, Ind. Eng. Chem. Res. 44 (2005) 2016-2026.

[15] S. Mahesh, B. Prasad, I.D. Mall, I.M. Mishra, Electrochemical degradation of pulp and paper mill wastewater. Part 1: COD and color removal, Ind. Eng. Chem. Res. 45 (2006) 2830-2839.

[16] A. Garg, I.M. Mishra, S. Chand, Effectiveness of coagulation and acid precipitation processes for the pre-treatment of diluted black liquor, J. Hazard. Mater. 180 (2010) 158-164.

[17] A.L. Ahmad, S.S. Wong, T.T. Teng, A. Zuhairi, Improvement of alum and PACl coagulation by polyacrylamides (PAMs) for the treatment of pulp and paper mill wastewater, Chem. Eng. J. 137 (2008) 510-517.

[18] D.H. Bache, E.N. Papavasilopoulos, Dewatering of alumino-humic sludge: impacts of hydroxide, Water Res. 37 (2003) 3289-3298.

[19] M.S.E. Abdo, K.T. Ewida, Y.M. Youssef, Recovery of alum from wasted sludge produced from water treatment plants, J. Environ. Sci. Health A 28 (1993) 1205-1216.

[20] M. Bishop, A.T. Rolan, T.L. Bailey, D.A. Cornwell, Testing of alum recovery for solids reduction and reuse, J. AWWA 79 (1987) 76-83.
[21] G.R. Xu, Z.C. Yan, Y.C. Wang, N. Wang, Recycle of alum recovered from water treatment sludge in chemically enhanced primary treatment, J. Hazard. Mater. 161 (2009) 663-669.

[22] C.W. Li, J.L. Lin, S.F. Kang, C.L. Liang, Acidification and alkalization of textile chemical sludge, Sep. Purif. Technol. 42 (2005) 31-37.

[23] APHA, Standard Methods for the Examination of Water and Wastewater, 21th ed., American Water Works Association and Water Environment Federation, 2005.

[24] T.C. Nelson, J.Y.C. Huang, D. Ramaswami, Decomposition of exopolysaccharide slime by a bacteriophage enzyme, Water Res. 22 (1988) 1185-1188.

[25] G. Li, S.H. Guo, F.M. Li, Treatment of oilfield produced water by anaerobic process coupled with micro-electrolysis, J. Environ. Sci. 22 (2010) 1875-1882.

[26] B. Jin, B. Wilén, P. Lant, Impacts of morphological, physical and chemical properties of sludge flocs on dewaterability of activated sludge, Chem. Eng. J. 98 (2004) 115-126.

[27] E.N. Papavasilopoulos, D.H. Bache, On the role of aluminium hydroxide in the conditioning of an alum sludge, Water Sci. Technol. 38 (1998) 33-40.

[28] G.W. Chen, W.W. Lin, D.J. Lee, Capillary suction time (CST) as a measure of sludge dewaterability, Water Sci. Technol. 34 (1996) 443-448.

[29] G.R. Chang, J.C. Liu, D.J. Lee, CO-conditioning and dewatering of chemical sludge and waste activated sludge, Water Res. 35 (2001) 786-794.

[30] C.C. Wu, J.J. Wu, Effect of charge neutralization on the dewatering performance of alum sludge by polymer conditioning, Water Sci. Technol. 44 (2001) 315-319.

[31] S. Verma, B. Prasad, I.M. Mishra, Pretreatment of petrochemical wastewater by coagulation and flocculation and the sludge characteristics, J. Hazard. Mater. 178 (2010) 1055-1064.

[32] T.J. Hwa, S. Jeyaseelan, Conditioning of oily sludges with municipal solid wastes incinerator fly ash, Water Sci. Technol. 35 (1997) 231-238.

[33] Y.Q. Zhao, Involvement of gypsum $\left(\mathrm{CaSO}_{4} \cdot 2 \mathrm{H}_{2} \mathrm{O}\right)$ in water treatment sludge dewatering: a potential benefit in disposal and reuse, Sep. Sci. Technol. 41 (2006) 2785-2794.

[34] C.Y. Chen, P.Y. Zhang, G.M. Zeng, J.H. Deng, Y. Zhou, H.F. Lu, Sewage sludge conditioning with coal fly ash modified by sulfuric acid, Chem. Eng. J. 158 (2010) 616-622.

[35] J. Benítez, A. Rodríguez, A. Suárez, Optimization technique for sewage sludge conditioning with polymer and skeleton builders, Water Res. 28 (1994) 2067-2073.

[36] I.G. Droppo, Structural controls on floc strength and transport, Can. J. Civ. Eng. 31 (2004) 569-578.

[37] T. Li, Z.Zhu, D.S. Wang, C.H. Yao, H.X. Tang, Characterization of floc size, strength and structure under various coagulation mechanisms, Powder Technol. 168 (2006) 104-110. 